\title{
The role of apoptosis-inducing receptors of the tumor necrosis factor family in thyroid cancer
}

\author{
C S Mitsiades, V Poulaki ${ }^{1}$ and $\mathbf{N}$ Mitsiades \\ Department of Medical Oncology, Dana-Farber Cancer Institute, Boston, Massachusetts 02115, USA \\ ${ }^{1}$ Angiogenesis Laboratory, Massachusetts Eye and Ear Infirmary, Harvard Medical School, 325 Cambridge Street, Boston, Massachusetts 02114, USA \\ (Requests for offprints should be addressed to N Mitsiades, Department of Medical Oncology, Dana-Farber Cancer Institute, Mayer Building, Room M555, \\ 44 Binney Street, Boston, Massachusetts 02115, USA; Email: mitsiades@netscape.net)
}

\begin{abstract}
The tumor necrosis factor (TNF) family comprises several ligands, such as the prototype TNF- $\alpha$, the Fas ligand (FasL) and TNF-related apoptosis-inducing ligand (TRAIL/Apo2L), which trigger apoptosis in susceptible cells by activating respective cell-surface receptors. The study of these cell death pathways has attracted significant attention in several fields, including that of thyroid cancer, because they participate in immune system function, as an arm of cell-mediated cytotoxicity, and because recombinant ligands are available for pharmacological use. TNF- $\alpha$ is a pluripotent cytokine that induces both proapoptotic and anti-apoptotic effects on thyroid carcinoma cells. FasL triggers apoptosis in other tumor types, but thyroid carcinoma cells are resistant to this effect. On the other hand, TRAIL potently and selectively kills thyroid carcinoma cells. Consequently, TRAIL is the only
\end{abstract}

member of the family with significant anticancer activity and an acceptable toxicity profile to be used as a novel therapy for thyroid cancer. The caspase inhibitor FLIP plays a significant role in negatively regulating receptorinduced apoptosis. Thelper 1-type cytokines, such as interferon- $\gamma, \mathrm{TNF}-\alpha$ and interleukin- $1 \beta$ increase the sensitivity of both normal and neoplastic thyrocytes to FasL and TRAIL. On the other hand, IGF-I and other growth/ survival factors produced in the local tumor microenvironment activate the phosphatidylinositol 3-kinase/Akt kinase pathway and exert an anti-apoptotic effect by upregulating several apoptosis inhibitors, including FLIP. Pharmacological modulation of apoptosis induced by FasL and TRAIL/Apo2L holds promise of therapeutic applications in human malignancies.

Journal of Endocrinology (2003) 178, 205-216

\section{Introduction}

In recent years, a surge in our knowledge about programmed cell death (apoptosis) has established its role in the regulation of tumorigenesis. Apoptosis is an active, energy-dependent process that mediates the elimination of cells that have developed improperly, or have sustained irreparable genetic damage (Thompson 1995). Therefore, inadequate cell death contributes, along with increased cell proliferation, to the emergence of hyperplasias and neoplasias (Thompson 1995, Zhivotovsky \& Orrenius 2003). Many oncogenes that participate in human cancer pathophysiology, such as ras and Bcl-2, represent overactive or overexpressed versions of proto-oncogenes that normally function by negatively regulating cell death. Moreover, several tumor suppressor genes that are frequently mutated or deleted in human cancers are, in their native form, inducers of apoptosis that safeguard the body from the emergence of neoplastic cells. A classic example is the 'guardian of the genome' p53, which, upon induction of DNA damage, is pivotal in the DNA repair process and, if the latter is not possible, triggers the apoptotic elimination of the damaged cell in order to avoid the emergence of mutant progeny (Lebedeva et al. 2003). p53 is inactivated in approximately $50 \%$ of human cancers, representing the most common genetic aberration in human malignancy. Anti-apoptotic molecules, such as Bcl-2 and BclxL, play pathogenetic roles not only in the emergence of various human malignancies, but contribute to their resistance to anticancer chemotherapy as well (Adams \& Cory 1998, Coultas \& Strasser 2003).

The apoptotic mechanism is triggered by intracellular as well as extracellular stimuli. Developmental cell death, which occurs during several stages of fetal development, is crucial for the natural involution of cells and structures that are no longer necessary for the embryo's development (Haanen \& Vermes 1996). In the cancer treatment setting, ionizing radiation and several chemotherapeutic agents 
induce DNA damage that subsequently triggers an intracellular signaling pathway that results in apoptosis (Thompson 1995, Zhivotovsky \& Orrenius 2003). Extracellular pro-apoptotic stimuli could be transduced by the stimulation (or, in other cases, the lack of stimulation) of cell-surface or nuclear receptors. For example, lack of growth/survival factors, frequently simulated in vitro by serum starvation, results in the activation of an intrinsic cell death pathway that is normally suppressed in the presence of paracrine stimulation (Mitsiades et al. 2002). Androgen withdrawal, commonly effected in vivo by surgical or chemical castration, triggers the programmed cell death pathway in both normal prostate glandular epithelia and androgen-dependent prostate cancer cells (Denmeade et al. 1996). In recent years, intense study has focused on the apoptosis signaling pathways triggered, via respective cell-surface receptors, by Fas ligand (FasL) and tumor necrosis factor (TNF)-related apoptosis-inducing ligand (TRAIL)/Apo2L, members of the TNF family of death ligands (Ozoren \& El-Deiry 2003). The present review will provide a background on the major players of the TNF family, will discuss their role in the pathogenesis of thyroid cancer and will present an update on the ongoing efforts to evaluate them as a potential anticancer therapeutic agent.

The important role of the Fas and TRAIL apoptotic pathways in thyroid autoimmunity (Hashimoto's and Graves' disease) will not be specifically addressed in this review. For a detailed analysis of that subject, the reader is directed to previous reviews (Andrikoula \& Tsatsoulis 2001, Mitsiades et al. 2001c, Stassi \& De Maria 2002, Tsatsoulis 2002).

\section{Background}

The TNF family comprises a growing number of extracellular ligands (CD40L, CD137L/4-1 BBL, CD134L/ OX40L, CD27L/CD70, CD30L, TNF- $\beta / \mathrm{LT}-\alpha, \mathrm{LT}-\beta$, TWEAK/Apo3L, TNF- $\alpha$, FasL, TRAIL) with complex, diverse and often overlapping roles in $\mathrm{B}$ and $\mathrm{T}$ cell development, lymphocyte activation, cytokine production, humoral immune response, cell-mediated cytotoxicity and apoptosis (Gruss 1996). Most are expressed on a broad spectrum of normal hematopoietic cells (especially after activation), as well as on many neoplastic cell lines (Gruss 1996, Vinay \& Kwon 1998). TNF- $\alpha$, FasL and TRAIL are the ligands most frequently involved in apoptotic signaling and are synthesized as type II transmembrane proteins (i.e. their amino-terminal end is intracellular), although most can also exist as soluble forms, whereby the carboxy-terminal extracellular portion is released via the enzymatic action of specific metalloproteinases (Moss et al. 1997, Mitsiades et al. 1999a, 2001d). In their active state, they exist as homotrimeric or even higher molecular weight complexes.
Their apoptosis-inducing receptors are type I transmembrane proteins (i.e. their amino-terminal end is extracellular) that belong in the $\mathrm{TNF} /$ nerve growth factor receptor superfamily. They harbor cysteine-rich extracellular domains and a cytoplasmic domain of approximately 70 amino acid residues is both necessary and sufficient for the induction of apoptosis (the death domain, DD) (Schulze-Osthoff et al. 1998). Upon cross-linking by its respective ligand, the receptor is oligomerized and recruits via its DD an adapter molecule. The aminoterminal region of the adapter molecule, named the death effector domain (DED) then recruits another DEDcontaining molecule, the pro-enzyme form of caspase- 8 or caspase-10, also known as FLICE (Fas-associating protein with a DD (FADD)-like interleukin-1 beta-converting enzyme) and FLICE-2 respectively, resulting in proteolytic autoactivation of the apical caspase (inducedproximity model) (Muzio et al. 1998, Salvesen \& Dixit 1999), which then transmits the apoptotic signal via the downstream apoptotic caspase cascade. This apoptotic cascade has been called 'instructive apoptosis' (Ashkenazi \& Dixit 1998, 1999) because it serves as a paracrine mechanism that enables a multicellular organism to instruct individual cells to die. This signaling pathway has a very high degree of specificity and is particularly important for the function of the immune system (Ashkenazi \& Dixit 1998, 1999).

\section{TNF- $\alpha$ and its receptors}

Human TNF- $\alpha$ exists as a $26 \mathrm{kDa}$ biologically active transmembrane protein expressed on the surface of a wide variety of hematopoietic and non-hematopoietic cells, and as a $17 \mathrm{kDa}$, also biologically active, soluble cytokine that is generated by proteolytic cleavage by TNF- $\alpha$-converting enzyme and circulates as a homotrimer (Gruss 1996, Moss et al. 1997). TNF- $\alpha$ signals through two different receptors, TNFRI/p55/CD120a and TNFRII/p75/ CD120b, which are expressed in most cells. TNFRI is a $55 \mathrm{kDa}$ transmembrane glycoprotein, with an extracellular region harboring four cysteine-rich motifs and a cytoplasmic domain containing a DD. Upon cross-linking, TNFRI binds the adapter molecule TNFR-associated DD, which promotes the recruitment and activation of pro-caspase-8, thus triggering the apoptotic cascade (Ashkenazi \& Dixit 1998). TNFRI can also trigger anti-apoptotic and activation pathways, namely the activation of the transcription factor $\mathrm{NF}-\kappa \mathrm{B}$ via the kinases receptor-interacting protein and $\mathrm{NF}-\mathrm{KB}$-inducing kinase, and the transcription factor AP-1, via recruitment of the TRAF2 (TNFR-associated factor-2) and activation of the MEKK1/JNKK/JNK pathway (Ashkenazi \& Dixit 1998). The role of the $75 \mathrm{kDa}$ TNFRII is still debated. It has been suggested that TNFRII binds TNF- $\alpha$ and transfers it to TNFRI, which then is activated and initiates its own signaling cascade (Tartaglia et al. 1993). However, direct 
TNFRII-mediated TNF- $\alpha$ signaling has also been demonstrated (Jupp et al. 2001). Moreover, by recruiting TRAF2 and inhibitors of apoptosis proteins (IAPs) that bind to it, TNFRII can prevent these anti-apoptotic proteins from interfering with the pro-apoptotic function of TNFRI and may accelerate TNFRI-dependent activation of caspase-8 (Fotin-Mleczek et al. 2002).

TNF- $\alpha$ is considered to play a pivotal role in the pathophysiology of a wide spectrum of immune-mediated conditions, such as shock and rheumatoid arthritis. Systemic administration of TNF- $\alpha$ results in a clinical picture that mimicks that of shock, and antibodies to TNF protect animals against the deleterious effects of i.v. injections of either lipopolysaccharide or live bacteria (Simpson \& Casey 1989, Tracey 1991). Two TNF- $\alpha$ antagonists have been approved for the treatment of rheumatoid arthritis by the United States Food and Drug Administration (FDA): a soluble p 75 TNF- $\alpha$ receptor fusion protein, consisting of a genetic fusion of recombinant soluble p75 TNF- $\alpha$ receptor to the $\mathrm{Fc}$ portion of $\operatorname{IgG}$ (Etanercept) (Weinblatt et al. 1999), and an anti-TNF- $\alpha$ antibody (Infliximab) (Lipsky et al. 2000). Infliximab has also been FDA approved for the treatment of Crohn's disease (Present et al. 1999).

\section{Fas and FasL}

Fas/Apo1/CD95 is widely expressed in normal and neoplastic tissues (Schulze-Osthoff et al. 1998). Upon crosslinking (by FasL or polyvalent antibodies), its cytoplasmic DD recruits the adapter FADD, also known as MORT1 (Schulze-Osthoff et al. 1998), which, via its aminoterminal DED, then recruits the pro-enzyme form of caspase-8 (Schulze-Osthoff et al. 1998). The aggregation of Fas, FADD and caspase-8, named the death-inducing signaling complex (DISC), catalyses the proteolytic autoactivation of caspase-8 (induced-proximity model) (Muzio et al. 1998, Salvesen \& Dixit 1999), which then activates the downstream caspase cascade.

FasL is expressed in activated $\mathrm{T}$ lymphocytes, where it participates in cell-mediated cytotoxicity against virally infected or transformed cells, as well as in the testis, the anterior chamber of the eye, the placenta and the brain (Schulze-Osthoff et al. 1998), where it contributes to the immune-privileged status of these organs by eliminating infiltrating lymphocytes. Fas-mediated apoptosis is, therefore, a key effector component of the immune system's antitumor surveillance function and also contributes to immune homeostasis, by eliminating autoreactive lymphocytic clones and mediating the suicidal elimination of activated immune cells at the end of an inflammatory reaction.

Fas and FasL also participate in the inflammatory destruction of target organs in several autoimmune disorders, including Hashimoto's thyroiditis (Giordano et al. 1997. Hammond et al. 1997, Arscott \& Baker 1998, Mitsiades et al. 1998b, Borgerson et al. 1999). Concurrent strong presence of both FasL and Fas has been detected on the surface of thyrocytes in Hashimoto's thyroiditis and they co-localize with the presence of apoptotic thyrocytes, with both being inversely proportional to the distance from infiltrating lymphocytes. These findings suggest that the FasL-Fas system is important for a suicidal/fratricidal apoptotic process in this setting and hence, in the pathogenesis of Hashimoto's thyroiditis. The infiltrating lymphocytes themselves express little to no FasL, implying that they are not directly engaged in the killing of thyrocytes with their own FasL (Mitsiades et al. 1998b). This finding agrees with earlier studies that determined that infiltrating activated T lymphocytes in Hashimoto's thyroiditis do not have direct cytotoxic potential, but rather induce thyrocyte apoptosis via production of cytokines (Weetman \& McGregor 1994). Lymphocytederived Thelper 1-type cytokines, specifically interferon (IFN) $-\gamma$, TNF- $\alpha$ and interleukin (IL) $-1 \beta$, can sensitize thyrocytes to Fas-mediated apoptosis (Bretz et al. 1999a), by upregulating Fas (Bretz et al. 1999a) and caspase-8 and -3 (Stassi et al. 2000). Moreover, expression of the apoptosis inhibitor Bcl-2 is downregulated in thyrocytes in Hashimoto's thyroiditis (Mitsiades et al. 1998b). Therefore, the follicular destruction in Hashimoto's thyroiditis appears to result from the imbalance between apoptosispromoting and -inhibiting molecules.

In regards to the antitumor activity of the Fas pathway, many (if not the majority of) tumor cell lines and primary cells have been reported to be resistant to its apoptotic activity. Several potential mechanisms for resistance to Fas-mediated apoptosis have been described in cancer cells, including downregulation of Fas protein expression, intracytoplasmic sequestration and failure of the receptor to translocate to the cell surface, production and secretion of a soluble form of 'decoy' receptor (either an alternatively spliced form of Fas or another soluble inhibitor of Fas activation (decoy receptor 3, DcR3)), or mutations of Fas, especially in the DD (Muschen et al. 2000). Obviously, different mechanisms may be operative in different patients and histological types of malignancies. A more widespread mechanism of resistance to Fas-mediated apoptosis is the overexpression of anti-apoptotic proteins. FLIP is an inhibitor of the Fas signaling pathway with a structure similar to caspase-8 (Irmler et al. 1997) that binds to FADD, yet is catalytically inactive and interferes with the proper formation of the DISC complex, thus representing a naturally occurring dominant negative form of caspase-8 (Fig. 1). Another Fas-inhibitory protein, Fasassociated phosphatase- 1 , which binds to the 15 carboxyterminal amino acids of the receptor, has been associated with resistance to Fas-mediated apoptosis (Myc et al. 1999), at least in some models.

Not only have many cancer cells become resistant to apoptosis induced through Fas, but, in many cases, they have acquired the ability to utilize this pathway to their advantage, by launching a 'Fas counterattack' against 


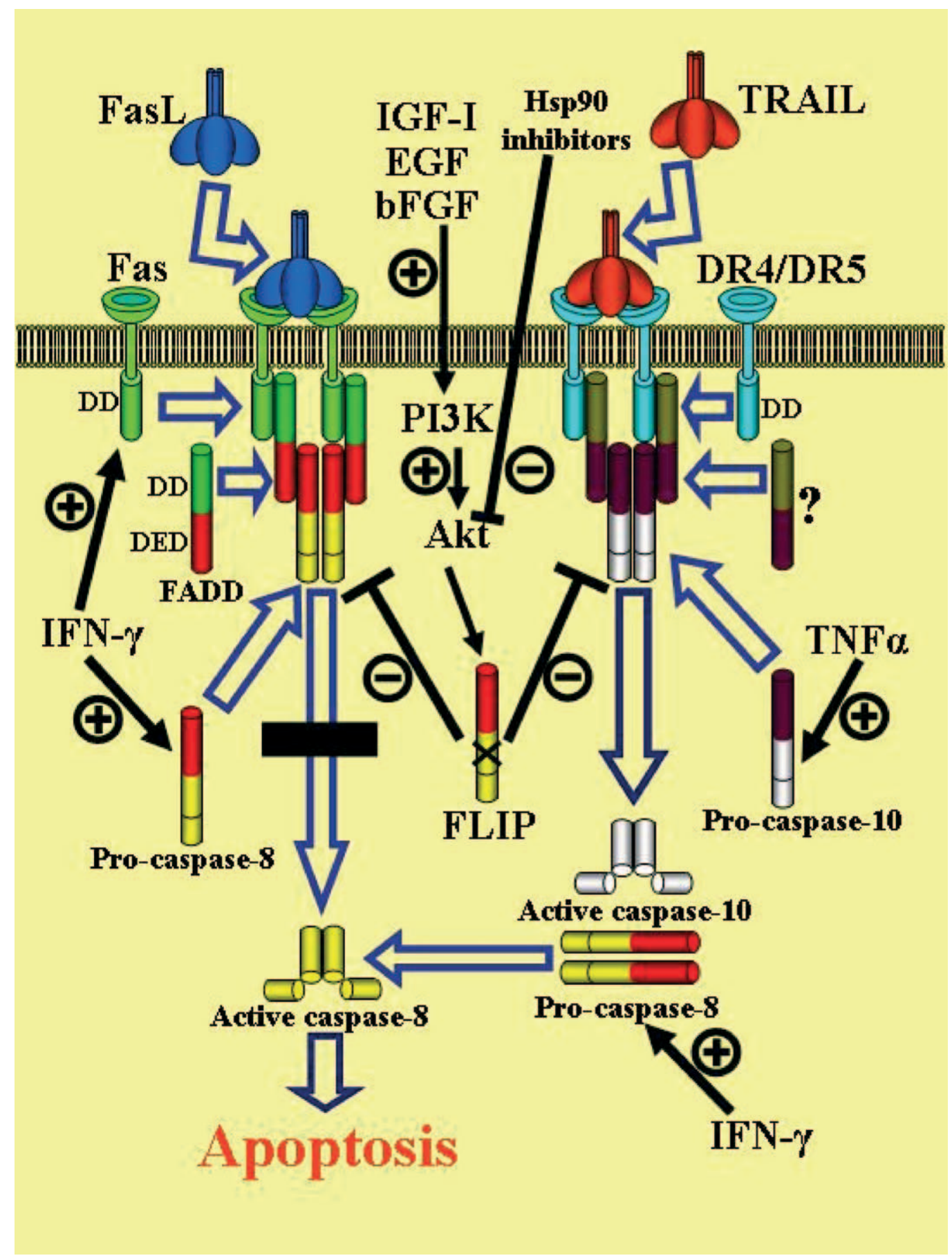


the host's immune system. In particular, FasL has been detected in a wide range of neoplasms, and, since activated lymphocytes are sensitive to Fas-mediated apoptosis, it has been postulated that it induces apoptosis of tumorinfiltrating immune cells (O'Connell et al. 1996, Gratas et al. 1997, 1998, Niehans et al. 1997, Mitsiades et al. 1998a,b). FasL-expressing tumor cell lines have been found to induce apoptosis in Fas-sensitive cells of lymphocytic origin in vitro, while apoptotic immune cells are present in the vicinity of FasL-positive neoplastic cells in vivo (Hahne et al. 1996). In support of a functional role for FasL in cancer progression and immune evasion in vivo, strong FasL expression correlated with increased aggressiveness and metastatic potential in several histological types of cancer (Mitsiades et al. 1998a). In most cases, this 'ectopic' expression of FasL by tumor cells coincides with their inherent resistance to Fas-mediated apoptosis, which protects them from a 'suicidal' death. Yet, there are cases where Fas-sensitive tumor cells produce their own FasL and yet avoid a Fas-FasL-mediated suicide because they cleave FasL into a soluble form through the action of a metalloproteinase and avoid its accumulation on their cell surface (Mitsiades et al. 2001b,d).

\section{TRAIL/Apo2L and its receptors}

TRAIL/Apo2L is a $32 \mathrm{kDa}$ transmembrane protein expressed on a wide range of normal fetal and adult tissues, suggesting the existence of a protective mechanism against its cytotoxicity in normal cells. This is supported by observations that TRAIL/Apo2L can induce apoptosis in transformed and malignant cells, but not in normal cells (Ashkenazi \& Dixit 1999). TRAIL induces apoptosis by interacting with two cell-surface receptors, DR4 (or TRAIL-R1) and DR5 (or TRAIL-R2) (Ashkenazi \& Dixit 1999). Three additional receptors for TRAIL, which cannot transduce an apoptotic signal, were also cloned: TRAIL-R3 (TRID, DcR1), TRAIL-R4 (TRUNDD, DcR2) and osteoprotegerin (Ashkenazi \& Dixit 1999). Initially, the presence of the mRNAs for these 'decoy' receptors was reported in non-neoplastic cells only, and it was proposed to be the reason for their resistance to TRAIL/Apo2L. However, subsequent studies revealed the presence of 'decoy' receptor mRNA and protein in cancer cells as well (Mitsiades et al. 2000, 2001a,b). Thus, the mechanism of resistance of normal cells to TRAIL/ Apo2L, as well as the functional significance of the 'decoy' receptors, are still elusive.

The selective nature of the anticancer activity of TRAIL was demonstrated with studies in mice and non-human primates (Ashkenazi et al. 1999, Walczak et al. 1999). However, subsequent reports have cautioned that recombinant TRAIL/Apo2L may kill normal human hepatocytes in vitro (Jo et al. 2000, Ozoren et al. 2000). It has been suggested that this finding was due to nonoptimized recombinant ligand preparations (Lawrence et al. 2001). Yet, clinical development of recombinant TRAIL has been delayed pending further studies. TRAIL-mimicking antibody-1, which binds to and activates TRAIL-R1, is currently being evaluated in phase I clinical trials in solid and hematological malignancies (Salcedo et al. 2002).

\section{The activity of death ligands against thyroid carcinomas}

\section{TNF- $a$}

TNF- $\alpha$ is produced locally by lymphocytes in areas of thyroid inflammation (Aust et al. 1996) and TNF- $\alpha$ receptors are expressed on thyroid carcinoma cells (Pang et al. 1989). Contrary to IFN- $\gamma$, which is consistently

Figure 1 Signaling pathways triggered by FasL and TRAIL in thyroid carcinomas. The cytoplasmic domain of Fas contains a domain necessary for the induction of apoptosis ('death domain', DD). Cross-linking by the trimeric FasL causes the recruitment of the DD-containing adapter molecule FADD through a homophilic interaction with the DD of Fas. The amino-terminal region of FADD, named the death effector domain (DED), serves as a docking surface for another DED-containing molecule, pro-caspase-8 (FLICE). The aggregation of Fas, FADD and pro-caspase-8 has been named the death-inducing signaling complex (DISC) and results in the proteolytic autoactivation of caspase- 8 and the formation of the active enzyme complex, which triggers a downstream apoptotic cascade. FLICE-inhibitory protein (FLIP) interferes with the proper formation of the DISC complex and inhibits the caspase- 8 activation and Fas-mediated apoptosis. FLIP has a structure similar to caspase-8, but is catalytically inactive, because it lacks critical amino acids at the active site and, thus, represents a naturally occurring dominant negative form of caspase-8. TRAIL/Apo2L induces apoptosis via two cell-surface receptors, DR4 (TRAIL-R1) and DR5 (TRAIL-R2). Both receptors contain cytoplasmic DD domains, through which they recruit FADD and pro-caspase-8, as shown in hematological malignancies. In thyroid carcinomas, TRAIL/Apo2L induces recruitment of pro-caspase-10 to the receptor signaling complex. The presence of an as yet unidentified adapter(s) with higher affinity for pro-caspase-10 and lower for FLIP may explain why thyroid carcinoma cell lines are resistant to FasL, yet very sensitive to TRAIL/Apo2L. According to this model, low levels of FLIP could suffice to block Fas-induced apoptosis, yet higher levels may be necessary to affect TRAIL/Apo2L signaling. Upon its activation at the receptor level, caspase-10 secondarily cleaves and activates caspase-8, thus amplifying the apoptotic cascade. Soluble factors produced by cellular components of the local microenvironment may modulate thyrocyte apoptosis. Pro-inflammatory Thelper 1-type cytokines, such as IFN- $\gamma$ and TNF- $\alpha$, are produced by infiltrating lymphocytes and stimulate the apoptotic pathway by increasing the protein levels of Fas and several caspases. IGF-I, bFGF and EGF, on the other hand, are present locally in thyroid tumors and upregulate FLIP expression via PI3K/Akt and decrease sensitivity to TRAIL without affecting TRAIL receptor levels. Members of the ansamycin antibiotic family, such as geldanamycin, which inhibit the chaperoning activity of the heat shock protein 90 (Hsp90), downregulate Akt and restore sensitivity to TRAIL. 
anti-proliferative and pro-apoptotic (Ohta et al. 1996), TNF- $\alpha$ has been reported to exert both pro- and antiapoptotic effects on thyroid carcinoma cell lines (Ohta et al. 1996, Pang et al. 1996). The anti-apoptotic effects should be attributed to the ability of TNF- $\alpha$ to activate $\mathrm{NF}-\kappa \mathrm{B}$, a transcription factor with cytoprotective actions, and to induce enzymes thought to be cytoprotective, such as manganese superoxide dismutase (MnSOD) (Pang et al. 1992). Cell lines resistant to the pro-apoptotic effect of TNF- $\alpha$ have increased basal expression of MnSOD (Pang et al. 1996). Moreover, TNF- $\alpha$ induces the expression of the anti-apoptotic Bcl-2 family member A1, in a time- and dose-dependent manner (Pang et al. 1997). It should be noted that TNF- $\alpha$ exerts on normal and malignant thyrocytes a strong sensitizing effect to FasL- and TRAILinduced apoptosis (Bretz et al. 1999a,b, 2002, Mitsiades et al. 2000, Poulaki et al. 2002b). This could be attributed to the induction by TNF- $\alpha$ of several death receptors (Fas, DR5) and caspases $(-3,-10)$ in thyrocytes (Poulaki et al. 2002b). Moreover, TNF- $\alpha$ has a strong stimulatory effect on the production of endogenous TRAIL by thyrocytes themselves (Bretz et al. 1999b, Poulaki et al. 2002b), an effect that further promotes apoptosis. TNF- $\alpha$ also reduced vascular endothelial growth factor secretion by anaplastic tumor cells in vitro (Wang et al. 2002). This suggests that TNF- $\alpha$ can inhibit the secretion of pro-angiogenic stimuli from neoplastic cells. It is also well-known that TNF- $\alpha$ directly induces apoptosis of endothelial cells (Madge \& Pober 2001). Therefore, although TNF- $\alpha$ alone has limited direct anticancer activity against thyroid carcinoma cell lines in vitro, it exerts anti-angiogenic effects and its combination with FasL and TRAIL provides a strong synergistic antitumor activity.

\section{FasL}

The issue of Fas expression in normal thyroid tissue has been at the center of a debate since an early report by Giordano et al. (1997), who suggested that Fas was absent in the tissues that they used as controls in their study of Hashimoto's thyroiditis. However, subsequent studies from several groups, using various laboratory techniques, have concluded the opposite, i.e. Fas is present (Leithauser et al. 1993, Tanimoto et al. 1995, Kawakami et al. 1996, Arscott et al. 1997, Mitsiades et al. 1998b, 2000) in normal thyroid follicular cells, even though the latter are resistant to Fas-mediated apoptosis under normal circumstances in vitro (Arscott et al. 1999). It has been suggested that since the 'control' thyroid tissue of the Giordano et al. (1997) study was derived from non-toxic goiters, it should not be considered truly normal (Mitsiades et al. 1998b, 1999b, Baker 1999).

Since Fas-mediated apoptosis is a key mechanism of $\mathrm{T}$ cell-mediated cytotoxicity against neoplastic cells and its inhibition contributes to tumor progression and metastasis, resistance to Fas is commonly found in tumor cells. In some cases, resistance is due to reduced cell-surface Fas expression (Hughes et al. 1997, Nambu et al. 1998). Fas expression has been reported to be low in thyroid nodules (Andrikoula et al. 2001), a finding that agrees with the results inadvertently obtained by Giordano et al. (1997) in their 'control' non-toxic goiter tissue. Thyrocytes from both normal and nodular tissue are resistant to Fasmediated cell death in vitro, but, even though the former can be sensitized by pro-inflammatory cytokines (see below), the latter often are not, suggesting the existence of additional blocks in their apoptotic pathway (Mezosi et al. 2002).

In the case of thyroid carcinomas, Fas is widely expressed, both in vivo and in vitro (Mitsiades et al. 2000), and may even be upregulated in neoplastic thyroid cells, compared with normal thyrocytes (Arscott et al. 1999). It is unclear what purpose this upregulation serves for the cancer cell, although it certainly does not pose an evolutionary disadvantage, because, similar to normal and goiter-derived thyrocytes, the Fas pathway is blocked in thyroid carcinoma cells. Indeed, cells from thyroid carcinoma lines are resistant to apoptosis induced by Fas cross-linking (Mitsiades et al. 1999b, 2000), similar to their normal counterparts (Arscott et al. 1997), and hardly any apoptotic nuclei are detected among thyroid carcinoma cells in vivo (Basolo et al. 1997, Mitsiades et al. 1999b).

Not only are thyroid carcinoma cells resistant to the apoptosis-inducing activity of FasL, but also they have been able to harness the activity of this pathway to their advantage. Several histological types of malignant tumors, including thyroid carcinomas, express FasL on their cell surface, and utilize it to escape immune surveillance, by inducing apoptosis of infiltrating lymphocytes (Hahne et al. 1996, Saas et al. 1997, Mitsiades et al. 1998a, 1999b, Rabinowich et al. 1998). In thyroid carcinomas, FasL mRNA and protein have been detected by in situ hybridization and immunohistochemistry in patient specimens, and by Western blotting and RT-PCR in thyroid carcinoma cell lines respectively (Mitsiades et al. 1999b). Moreover, cells from thyroid carcinoma lines can kill Fas-sensitive Jurkat cells in a FasL-dependent manner in co-culture (Mitsiades et al. 1999b). In papillary carcinomas in vivo, high levels of FasL expression correlate independently with aggressive histology and unfavorable clinical presentation (Mitsiades et al. 1999b). These observations point to FasL as a cytolytic molecule that contributes to thyroid carcinoma aggressiveness by launching a 'counterattack' against the host's immune system. The carcinoma cells themselves are not affected by their own FasL, due to their inherent resistance to Fas-mediated apoptosis (Mitsiades et al. 1999b, 2000).

\section{TRAIL}

The constitutive resistance of thyroid carcinomas to Fasmediated apoptosis, combined with the systemic toxicity 
of Fas activation (Ogasawara et al. 1993), precludes the clinical use of FasL against thyroid carcinomas (Ashkenazi \& Dixit 1999). However, the discovery that another death ligand, TRAIL/Apo2L, potently and selectively targets neoplastic cells (Ashkenazi et al. 1999, Walczak et al. 1999) sparked widespread interest in its use as a novel anticancer therapeutic modality. The apoptosis-inducing TRAIL receptors TRAIL-R1 and TRAIL-R2 are broadly expressed in thyroid carcinomas and thyroid carcinoma cell lines (Mitsiades et al. 2000). Importantly, TRAIL/ Apo2L effectively kills most thyroid cell lines tested, including those originating from anaplastic carcinomas (Ahmad \& Shi 2000, Mitsiades et al. 2000). Also, the presence of p53 mutations did not impede the anticancer activity of TRAIL (Mitsiades et al. 2000), suggesting that it can still be effective against poorly differentiated cells that frequently harbor defects in the p53 pathway. Therefore, TRAIL/Apo2L is a very promising new agent against thyroid cancer that may overcome resistance to current therapeutic modalities.

Both caspase- 8 and the closely related caspase- 10 have been implicated as the apical caspases of TRAIL-induced apoptosis in different models (Kischkel et al. 2000, Sprick et al. 2000, Mitsiades et al. 2001b). In thyroid carcinoma cell lines, TRAIL/Apo2L induces rapid recruitment of caspase-10 to the TRAIL receptor(s) and its activation, followed by activation of caspase- 8 and -3 (Mitsiades et al. 2000) (Fig. 1). It appears, therefore, that the initial step of the TRAIL apoptotic cascade is tissue-dependent. This finding also indicates that endogenous caspase- 8 can be activated in thyroid carcinoma cells by other caspases, thus overriding the apoptotic block that occurs within the Fas pathway.

\section{Intracellular regulation of death receptor signaling in thyroid carcinoma}

As mentioned previously, thyroid carcinomas exhibit differential response to stimulation with the various cellsurface death ligands of the TNF family, with TNF- $\alpha$ reported to activate both pro-apoptotic and anti-apoptotic pathways, whereas TRAIL is potently pro-apoptotic and FasL is unable to induce apoptosis. The complete resistance of thyroid carcinoma cell lines to FasL-induced apoptosis is due to the inability of Fas to recruit and activate caspase-8 at the DISC (Fig. 1) (Mitsiades et al. 2000), which is a necessary step for the effective transduction of the apoptotic signal. Further support for the localization of the apoptotic block at a level upstream of caspase- 8 is provided by experiments where transfection of a constitutively active caspase- 8 construct resulted in apoptosis of papillary carcinoma cells (Mitsiades et al. 2000). Because the protein synthesis inhibitor cycloheximide can sensitize normal thyrocytes (Arscott et al. 1997) and papillary, follicular and anaplastic carcinoma cell lines (Mitsiades et al. 2000) to Fas-mediated cell death, it appears that Fas itself is genetically intact (thus excluding the possibility of mutations) and its function is attenuated by the presence of (a) short-lived inhibitory protein(s). FLIP is a well-known inhibitor of Fas-mediated apoptosis and could play this role, as it is present in thyroid carcinoma cells both in vivo and in vitro and co-immunoprecipitates with Fas (Mitsiades et al. 2000). Moreover, specific downregulation of FLIP, after transfection of an antisense oligonucleotide, sensitizes thyroid carcinoma cell lines to Fas-mediated apoptosis (C S Mitsiades, V Poulaki \& N Mitsiades, unpublished observations).

TRAIL, on the other hand, potently triggers apoptosis in carcinoma cell lines originating from the thyroid follicular epithelium, but not in normal thyrocytes (Mitsiades et al. 2000). Specifically, recombinant TRAIL induced apoptosis in eight of eight cell lines originating from papillary carcinomas, and in two of two cell lines originating from anaplastic carcinomas. TRAIL activated caspase-10 at the receptor level and triggered a caspasemediated apoptotic cascade (Mitsiades et al. 2000). Resistance among cancer cell lines is rare and, when present, can be reversed by cycloheximide, suggesting, again, a role for (a) short-lived apoptosis inhibitor(s). The previously proposed hypothesis that the TRAIL receptors TRAIL-R3 (DcR1) and TRAIL-R4 (DcR2), which cannot transmit a pro-apoptotic signal, serve as 'decoy' receptors (Ashkenazi \& Dixit 1999), cannot provide an explanation for TRAIL resistance, because both receptors are expressed in normal and neoplastic thyrocytes in vitro and in vivo and their presence does not correlate with resistance to TRAIL (Mitsiades et al. 2000). Thus, the inhibitor(s) of TRAIL signaling must be intracellular. Similar to results in other tissues (Thome et al. 1997), the caspase-8 inhibitor FLIP modulates TRAIL-induced apoptosis in thyroid carcinomas (Poulaki et al. 2002b). Thyroid carcinoma cells selected in vitro for resistance to TRAIL exhibited higher FLIP levels than parental cells. Cycloheximide downregulated FLIP expression and restored TRAIL sensitivity (Poulaki et al. 2002b). Finally, sensitivity to TRAIL in this model was restored in vitro upon downregulation of FLIP by transfection with a specific anti-sense oligonucleotide (Poulaki et al. 2002b).

It is thus possible that FLIP plays an inhibitory role in both FasL- and TRAIL-induced apoptosis in thyroid carcinomas. Since the latter ligand is significantly more effective against thyroid carcinomas than the former, it appears that the threshold for inhibition of apoptosis is lower in the former pathway. For example, low levels of FLIP could suffice to block Fas-induced apoptosis, yet higher levels may be necessary to affect TRAIL/Apo2L signaling. This model could be explained by differential affinity of the inhibitor for the respective ligandreceptor-caspase signaling complexes. It should be noted that, contrary to the Fas pathway, where the FADD 
adapter molecule is the unequivocal mediator of DISC formation, it is yet unclear what molecule plays the adapter role for the TRAIL apoptotic pathway in neoplastic thyrocytes. If that, yet unidentified, adapter has lower affinity for FLIP than FADD does, then inhibition of the TRAIL pathway would require higher levels of FLIP than the Fas pathway.

\section{The role of the local microenvironment}

One of the major advances in our understanding of cancer pathophysiology in recent years is the realization that the behavior of the neoplastic cell is strongly influenced by direct or indirect interactions with other components of the tumor, such as fibroblasts, lymphocytes or endothelial cells. As a result, the behavior of cultured cancer cells under baseline conditions ex vivo may not recapitulate all relevant aspects of their in vivo phenotype. The role of the local microenvironment in thyroid cancer is striking in cases of papillary carcinomas with extensive lymphocytic infiltrates ('peri-tumoral thyroiditis'), which are associated with a more favorable prognosis (Baker 1995). Pro-inflammatory Thelper 1-type cytokines produced by the infiltrating lymphocytes (IFN- $\gamma$, TNF- $\alpha$ and IL-1 $\beta$ ) have a significant effect on tumor cell behavior and sensitivity to apoptosis. These cytokines stimulate the apoptotic pathway at various levels, as they increase the protein levels of Fas (Mitsiades et al. 2000), and caspase-8 and -3 (Stassi et al. 2000, Poulaki et al. 2002b). As a result, they increase sensitivity of neoplastic (and normal) thyrocytes to FasL (Bretz et al. 1999a, Mitsiades et al. 2000) and TRAIL (Bretz et al. 1999b, 2002, Poulaki et al. 2002b). Mezosi et al. (2002), however, recently reported that this sensitizing effect of Thelper 1 cytokines was not observed in many cases of goiter-derived thyrocytes, raising the possibility of a different mechanism of apoptosis regulation in thyroid goiter.

Contrary to this pro-apoptotic role of infiltrating lymphocytic populations, other cellular components of the local microenvironment produce soluble factors that may exert an anti-apoptotic effect. For example, in thyroid neoplasms, basic fibroblast growth factor (bFGF) is produced by thyroid carcinoma tumor cells (Daa et al. 1993, Kodama et al. 1994, Shingu et al. 1994, 1998, Eggo et al. 1995) and stromal cells (Shingu et al. 1998). Thyroid carcinoma cells also express FGF receptor-1 (Shingu et al. 1998) and bFGF stimulates their proliferation in vitro (Daa et al. 1993). These results indicate that bFGF plays an important role in the development of papillary carcinoma of the thyroid via an autocrine/paracrine loop (Daa et al. 1993). Moreover, epidermal growth factor (EGF) and its receptor EGF-R were widely expressed in normal thyroid and in all thyroid neoplasms (Makinen et al. 1988, van der Laan et al. 1995). The EGF-R immunostaining is stronger in neoplastic cells than in adjacent normal thyroid tissue (Westermark et al. 1996). Differentiated thyroid cancers bind more EGF than normal thyroid tissue and EGF stimulates the growth and invasion of differentiated thyroid cancer cells in culture and in nude mice (Hoelting et al. 1994). In papillary thyroid carcinomas, cytoplasmic EGF-R immunostaining has been demonstrated to be an independent indicator of tumor recurrence (Akslen et al. 1993, Akslen \& Varhaug 1995), suggesting it may play a role in the pathogenesis of human thyroid carcinoma (Kanamori et al. 1989). Finally, the insulin-like growth factor (IGF)/IGF-receptor pathway also plays an important role in the pathogenesis of thyroid cancer. Thyroid carcinoma cells express the IGF-I receptor and IGF-I is produced locally in thyroid tumors by stromal cells in amounts significantly higher than in normal tissue (Vella et al. 2001). bFGF, EGF and IGF-I have been demonstrated to activate the phosphatidylinositol 3-kinase (PI3K)/Akt kinase pathway in vitro (Chen et al. 2000, Poulaki et al. 2002b, Andl et al. 2003). Akt overactivation has been reported in thyroid neoplasms (Ringel et al. 2001) and has been shown to promote resistance to apoptosis (De Vita et al. 2000). Stimulation of thyroid carcinoma cell lines with IGF-I in vitro upregulates expression of the apoptosis inhibitors FLIP, cIAP2 and XIAP; downregulates the pro-apoptotic Bax; increases proliferation (Saito et al. 2001); and decreases sensitivity to TRAIL in a PI3K/Akt-dependent manner without affecting TRAIL receptor levels (Poulaki et al. 2002b). bFGF and EGF also have protective effects against TRAIL-induced apoptosis in thyroid carcinomas (Poulaki et al. 2002b). These observations provide another mechanism of functional resistance to death receptor-induced apoptosis, i.e. increased survival of the tumor cells in vivo due to paracrine/autocrine loops in the absence of direct genetic alterations of apoptosis-related genes in the tumor cells themselves.

Understanding the role of the microenvironment on tumor cell apoptosis and response to therapy suggested that targeting both the neoplastic cell and the microenvironment would provide a better anticancer effect and thus should be the basis for novel therapies. For example, the ansamycin antibiotic geldanamycin, which inhibits the chaperoning activity of heat shock protein 90 (Basso et al. 2002, Dunn 2002), reduces the intracellular levels and activity of Akt (Poulaki et al. 2002a) and attenuates the anti-apoptotic effect of IGF-I in a thyroid carcinoma cell line in vitro (Poulaki et al. 2002a), thus providing the rationale for future clinical use of such agents to specifically block the anti-apoptotic sequelae of IGF-I on thyroid carcinoma cells. Geldanamycin analogs, such as 17-allyl-aminogeldanamycin, have been tested in phase I clinical trials for solid tumors, with a favorable profile of side-effects and preliminary evidence of antitumor activity (Munster et al. 2001).

\section{Conclusions: future directions and therapeutic opportunities}

In thyroid cancer, the restoration of a pro-apoptotic state in neoplastic cells would enhance the effectiveness of 
anticancer therapy and the host's own immune surveillance. Systemic administration of TNF- $\alpha$ or FasL is unlikely to be used therapeutically in the treatment of thyroid cancer, due to low, if any, antitumor activity and unacceptable toxicity. However, the discovery of the efficacy and selectivity of the anti-neoplastic action of TRAIL/Apo2L has led to a very promising candidate therapeutic reagent. A TRAIL-mimicking antibody, which binds to and activates TRAIL-R1, is currently being evaluated in phase I clinical trials in solid and hematological malignancies. Furthermore, novel therapies such as the geldanamycin analogs, which target locally produced survival factors and their signaling pathway, such as that of IGF-I, could exert increased antineoplastic activity clinically by targeting both the tumor cells and their microenvironment.

Yet, several questions still remain. For example, the mechanism of resistance of normal cells to TRAIL/Apo2L is still unknown, as several studies in multiple models have clearly dismissed the role of the 'decoy' receptors. So why is TRAIL so selectively potent against cancer cells? The fact that thyroid carcinoma cells have become sensitive to an apoptotic agent that spared their non-malignant precursors is difficult to explain and the only likely hypothesis is that sensitivity to TRAIL/Apo2L is strongly linked to an indispensable part of the neoplastic phenotype. The recent involvement of cell cycle regulation in the modulation of TRAIL/Apo2L sensitivity supports this hypothesis (Jin \& El-Deiry 2001).

Finally, medullary thyroid carcinoma cells, in agreement with their different histogenetic origin, exhibit increased resistance to death-receptor induced apoptosis, even in the presence of sensitizing cytokines. This suggests a different regulation of apoptotic pathways in these cells and correlates with their resistance to chemotherapeutic agents in the clinical setting. Considering the poor clinical outcome of metastatic medullary carcinoma, the investigation of the apoptotic defect in these tumor cells is particularly important, as it could lead to urgently needed novel therapies.

\section{Acknowledgement}

Supported by the Propondis Foundation, Piraeus, Greece.

\section{References}

Adams JM \& Cory S 1998 The Bcl-2 protein family: arbiters of cell survival. Science 281 1322-1326.

Ahmad M \& Shi Y 2000 TRAIL-induced apoptosis of thyroid cancer cells: potential for therapeutic intervention. Oncogene 19 3363-3371.

Akslen LA \& Varhaug JE 1995 Oncoproteins and tumor progression in papillary thyroid carcinoma: presence of epidermal growth factor receptor, c-erbB-2 protein, estrogen receptor related protein, p21-ras protein, and proliferation indicators in relation to tumor recurrences and patient survival. Cancer 76 1643-1654.
Akslen LA, Myking AO, Salvesen H \& Varhaug JE 1993 Prognostic impact of EGF-receptor in papillary thyroid carcinoma. British Journal of Cancer 68 808-812.

Andl CD, Mizushima T, Nakagawa H, Oyama K, Harada H, Chruma K, Herlyn M \& Rustgi AK 2003 Epidermal growth factor receptor mediates increased cell proliferation, migration, and aggregation in esophageal keratinocytes in vitro and in vivo. Journal of Biological Chemistry 278 1824-1830.

Andrikoula M \& Tsatsoulis A 2001 The role of Fas-mediated apoptosis in thyroid disease. European Journal of Endocrinology 144 561-568.

Andrikoula M, Vartholomatos G, Tsangaris GT, Bafa M, Tzortzatou-Stathopoulou F \& Tsatsoulis A 2001 Fas and Bcl-2 protein expression in thyrocytes of patients with nodular goiter. European Journal of Endocrinology 145 403-407.

Arscott PL \& Baker JR Jr 1998 Apoptosis and thyroiditis. Clinical Immunology and Immunopathology 87 207-217.

Arscott PL, Knapp J, Rymaszewski M, Bartron JL, Bretz JD, Thompson NW \& Baker JR Jr 1997 Fas (APO-1, CD95)-mediated apoptosis in thyroid cells is regulated by a labile protein inhibitor. Endocrinology 138 5019-5027.

Arscott PL, Stokes T, Myc A, Giordano TJ, Thompson NW \& Baker JR Jr 1999 Fas (CD95) expression is up-regulated on papillary thyroid carcinoma. Journal of Clinical Endocrinology and Metabolism 84 4246-4252.

Ashkenazi A \& Dixit VM 1998 Death receptors: signaling and modulation. Science 281 1305-1308.

Ashkenazi A \& Dixit VM 1999 Apoptosis control by death and decoy receptors. Current Opinion in Cell Biology 11 255-260.

Ashkenazi A, Pai RC, Fong S, Leung S, Lawrence DA, Marsters SA, Blackie C, Chang L, McMurtrey AE, Hebert A et al. 1999 Safety and antitumor activity of recombinant soluble Apo2 ligand. Journal of Clinical Investigation 104 155-162.

Aust G, Heuer M, Laue S, Lehmann I, Hofmann A, Heldin NE \& Scherbaum WA 1996 Expression of tumour necrosis factor-alpha (TNF-alpha) mRNA and protein in pathological thyroid tissue and carcinoma cell lines. Clinical and Experimental Immunology 105 148-154.

Baker JR Jr 1995 The immune response to papillary thyroid cancer. Journal of Clinical Endocrinology and Metabolism 80 3419-3420.

Baker JR Jr 1999 Dying (apoptosing?) for a consensus on the Fas death pathway in the thyroid. Clinical Endocrinology and Metabolism 84 2593-2595.

Basolo F, Pollina L, Fontanini G, Fiore L, Pacini F \& Baldanzi A 1997 Apoptosis and proliferation in thyroid carcinoma: correlation with bcl-2 and p53 protein expression. British Journal of Cancer $\mathbf{7 5}$ $537-541$.

Basso AD, Solit DB, Munster PN \& Rosen N 2002 Ansamycin antibiotics inhibit Akt activation and cyclin $\mathrm{D}$ expression in breast cancer cells that overexpress HER2. Oncogene 21 1159-1166.

Borgerson KL, Bretz JD \& Baker JR Jr 1999 The role of Fas-mediated apoptosis in thyroid autoimmune disease. Autoimmunity 30 251-264.

Bretz JD, Arscott PL, Myc A, Baker JR Jr 1999a Inflammatory cytokine regulation of Fas-mediated apoptosis in thyroid follicular cells. Journal of Biological Chemistry 274 25433-25438.

Bretz JD, Rymaszewski M, Arscott PL, Myc A, Ain KB, Thompson NW \& Baker JR Jr 19996 TRAIL death pathway expression and induction in thyroid follicular cells. Journal of Biological Chemistry 274 23627-23632.

Bretz JD, Mezosi E, Giordano TJ, Gauger PG, Thompson NW \& Baker JR Jr 2002 Inflammatory cytokine regulation of TRAILmediated apoptosis in thyroid epithelial cells. Cell Death and Differentiation 9 274-286.

Chen Y, Li X, Eswarakumar VP, Seger R \& Lonai P 2000 Fibroblast growth factor (FGF) signaling through PI 3-kinase and Akt/PKB is required for embryoid body differentiation. Oncogene 19 3750-3756.

Coultas L \& Strasser A 2003 The role of the Bcl-2 protein family in cancer. Seminars in Cancer Biology 13 115-123. 
Daa T, Kodama M, Kashima K, Yokoyama S, Nakayama I \& Noguchi S 1993 Identification of basic fibroblast growth factor in papillary carcinoma of the thyroid. Acta Pathologica Japonica $\mathbf{4 3}$ 582-589.

De Vita G, Berlingieri MT, Visconti R, Castellone MD, Viglietto G, Baldassarre G, Zannini M, Bellacosa A, Tsichlis PN, Fusco A et al. $2000 \mathrm{Akt} /$ protein kinase B promotes survival and hormoneindependent proliferation of thyroid cells in the absence of dedifferentiating and transforming effects. Cancer Research $\mathbf{6 0}$ 3916-3920.

Denmeade SR, Lin XS \& Isaacs JT 1996 Role of programmed (apoptotic) cell death during the progression and therapy for prostate cancer. [Erratum appears in Prostate 199628 414.] Prostate 28 251-265.

Dunn FB 2002 Heat shock protein inhibitor shows antitumor activity. JNCI Cancer Spectrum 94 1194-1195.

Eggo MC, Hopkins JM, Franklyn JA, Johnson GD, Sanders DS \& Sheppard MC 1995 Expression of fibroblast growth factors in thyroid cancer. Journal of Clinical Endocrinology and Metabolism 80 1006-1011.

Fotin-Mleczek M, Henkler F, Samel D, Reichwein M, Hausser A, Parmryd I, Scheurich P, Schmid JA \& Wajant H 2002 Apoptotic crosstalk of TNF receptors: TNF-R2-induces depletion of TRAF2 and IAP proteins and accelerates TNF-R1-dependent activation of caspase-8. Journal of Cell Science 115 2757-2770.

Giordano C, Stassi G, De Maria R, Todaro M, Richiusa P, Papoff G, Ruberti G, Bagnasco M, Testi R \& Galluzzo A 1997 Potential involvement of Fas and its ligand in the pathogenesis of Hashimoto's thyroiditis. Science 275 960-963.

Gratas C, Tohma Y, Van Meir EG, Klein M, Tenan M, Ishii N, Tachibana O, Kleihues P \& Ohgaki H 1997 Fas ligand expression in glioblastoma cell lines and primary astrocytic brain tumors. Brain Pathology 7 863-869.

Gratas C, Tohma Y, Barnas C, Taniere P, Hainaut P \& Ohgaki H 1998 Up-regulation of Fas (APO-1/CD95) ligand and downregulation of Fas expression in human esophageal cancer. Cancer Research 58 2057-2062.

Gruss H 1996 Molecular, structural, and biological characteristics of the tumor necrosis factor ligand superfamily. International Journal of Clinical and Laboratory Research 26 143-159.

Haanen C \& Vermes I 1996 Apoptosis: programmed cell death in fetal development. European Journal of Obstetrics, Gynecology, and Reproductive Biology 64 129-133.

Hahne M, Rimoldi D, Schroter M, Romero P, Schreier M, French LE, Schneider P, Bornand T, Fontana A, Lienard D et al. 1996 Melanoma cell expression of Fas(Apo-1/CD95) ligand: implications for tumor immune escape. Science 274 1363-1366.

Hammond LJ, Lowdell MW, Cerrano PG, Goode AW, Bottazzo GF \& Mirakian R 1997 Analysis of apoptosis in relation to tissue destruction associated with Hashimoto's autoimmune thyroiditis. Journal of Pathology 182 138-144.

Hoelting T, Siperstein AE, Clark OH \& Duh QY 1994 Epidermal growth factor enhances proliferation, migration, and invasion of follicular and papillary thyroid cancer in vitro and in vivo. Journal of Clinical Endocrinology and Metabolism 79 401-408.

Hughes SJ, Nambu Y, Soldes OS, Hamstra D, Rehemtulla A, Iannettoni MD, Orringer MB \& Beer DG 1997 Fas/APO-1 (CD95) is not translocated to the cell membrane in esophageal adenocarcinoma. Cancer Research 57 5571-5578.

Irmler M, Thome M, Hahne M, Schneider P, Hofmann K, Steiner V, Bodmer JL, Schroter M, Burns K, Mattmann C et al. 1997 Inhibition of death receptor signals by cellular FLIP. Nature 388 190-195.

Jin Z \& El-Deiry WS 2001 Enhanced sensitivity of G1 arrested human cancer cells suggests a novel therapeutic strategy using a combination of simvastatin and TRAIL. Proceedings of the American Association for Cancer Research 42438.
Jo M, Kim TH, Seol DW, Esplen JE, Dorko K, Billiar TR \& Strom SC 2000 Apoptosis induced in normal human hepatocytes by tumor necrosis factor-related apoptosis-inducing ligand. Nature Medicine 6 564-567.

Jupp OJ, McFarlane SM, Anderson HM, Littlejohn AF, Mohamed AA, MacKay RH, Vandenabeele P \& MacEwan DJ 2001 Type II tumour necrosis factor-alpha receptor (TNFR2) activates c-Jun N-terminal kinase (JNK) but not mitogen-activated protein kinase (MAPK) or p38 MAPK pathways. Biochemical Journal 359 525-535.

Kanamori A, Abe Y, Yajima Y, Manabe Y \& Ito K 1989 Epidermal growth factor receptors in plasma membranes of normal and diseased human thyroid glands. Journal of Clinical Endocrinology and Metabolism 68 899-903.

Kawakami A, Eguchi K, Matsuoka N, Tsuboi M, Kawabe Y, Ishikawa N, Ito K \& Nagataki S 1996 Thyroid-stimulating hormone inhibits Fas antigen-mediated apoptosis of human thyrocytes in vitro. Endocrinology 137 3163-3169.

Kischkel FC, Lawrence DA, Chuntharapai A, Schow P, Kim KJ \& Ashkenazi A 2000 Apo2L/TRAIL-dependent recruitment of endogenous FADD and caspase- 8 to death receptors 4 and 5 . Immunity 12 611-620.

Kodama M, Daa T, Kashima K, Yokoyama S, Nakayama I \& Noguchi S 1994 Immunohistochemical localization of acidic and basic fibroblast growth factors in human benign and malignant thyroid lesions. Japanese Journal of Clinical Oncology 24 66-73.

Lawrence D, Shahrokh Z, Marsters S, Achilles K, Shih D, Mounho B, Hillan K, Totpal K, DeForge L, Schow P et al. 2001 Differential hepatocyte toxicity of recombinant Apo2L/TRAIL versions. Nature Medicine 7 383-385.

Lebedeva IV, Su Z-Z, Sarkar D \& Fisher PB 2003 Restoring apoptosis as a strategy for cancer gene therapy: focus on p53 and mda-7. Seminars in Cancer Biology 13 169-178.

Leithauser F, Dhein J, Mechtersheimer G, Koretz K, Bruderlein S, Henne C, Schmidt A, Debatin KM, Krammer PH \& Moller P 1993 Constitutive and induced expression of APO-1, a new member of the nerve growth factor/tumor necrosis factor receptor superfamily, in normal and neoplastic cells. Laboratory Investigation $69415-429$.

Lipsky PE, van der Heijde DM, St Clair EW, Furst DE, Breedveld FC, Kalden JR, Smolen JS, Weisman M, Emery P, Feldmann M et al. 2000 Infliximab and methotrexate in the treatment of rheumatoid arthritis. Anti-Tumor necrosis factor trial in rheumatoid arthritis with concomitant therapy study group [Comment]. New England Journal of Medicine 343 1594-1602.

Madge LA \& Pober JS 2001 TNF signaling in vascular endothelial cells. Experimental and Molecular Pathology 70 317-325.

Makinen T, Pekonen F, Franssila K \& Lamberg BA 1988 Receptors for epidermal growth factor and thyrotropin in thyroid carcinoma. Acta Endocrinologica 117 45-50.

Mezosi E, Yamazaki H, Bretz JD, Wang SH, Arscott PL, Utsugi S, Gauger PG, Thompson NW \& Baker JR Jr 2002 Aberrant apoptosis in thyroid epithelial cells from goiter nodules. Journal of Clinical Endocrinology and Metabolism 87 4264-4272.

Mitsiades N, Poulaki V, Kotoula V, Leone A \& Tsokos M 1998a Fas ligand is present in tumors of the Ewing's sarcoma family and is cleaved into a soluble form by a metalloproteinase. American Journal of Pathology 153 1947-1956.

Mitsiades N, Poulaki V, Kotoula V, Mastorakos G, Tseleni-Balafouta S, Koutras DA \& Tsokos M 1998b Fas/Fas ligand up-regulation and Bcl-2 down-regulation may be significant in the pathogenesis of Hashimoto's thyroiditis. Journal of Clinical Endocrinology and Metabolism 83 2199-2203.

Mitsiades N, Poulaki V, Leone A \& Tsokos M 1999a Fas-mediated apoptosis in Ewing's sarcoma cell lines by metalloproteinase inhibitors. Journal of the National Cancer Institute 91 1678-1684. 
Mitsiades N, Poulaki V, Mastorakos G, Tseleni-Balafouta ST, Kotoula V, Koutras DA \& Tsokos M 1999b Fas ligand expression in thyroid carcinomas: a potential mechanism of immune evasion. Journal of Clinical Endocrinology and Metabolism 84 2924-2932.

Mitsiades N, Poulaki V, Tseleni-Balafouta S, Koutras DA \& Stamenkovic I 2000 Thyroid carcinoma cells are resistant to FAS-mediated apoptosis but sensitive to tumor necrosis factorrelated apoptosis-inducing ligand. Cancer Research $604122-4129$.

Mitsiades CS, Treon SP, Mitsiades N, Shima Y, Richardson P, Schlossman R, Hideshima T \& Anderson KC 2001a TRAIL/ Apo2L ligand selectively induces apoptosis and overcomes drug resistance in multiple myeloma: therapeutic applications. Blood $\mathbf{9 8}$ 795-804.

Mitsiades N, Poulaki V, Mitsiades C \& Tsokos M $2001 b$ Ewing's sarcoma family tumors are sensitive to tumor necrosis factor-related apoptosis-inducing ligand (TRAIL) and express DR4 and DR5 receptors. Cancer Research 61 2704-2712.

Mitsiades N, Poulaki V, Mitsiades CS, Koutras DA \& Chrousos GP 2001c Apoptosis induced by FasL and TRAIL/Apo2L in the pathogenesis of thyroid diseases. Trends in Endocrinology and Metabolism 12 384-390.

Mitsiades N, Yu WH, Poulaki V, Tsokos M \& Stamenkovic I 2001d Matrix metalloproteinase-7-mediated cleavage of Fas ligand protects tumor cells from chemotherapeutic drug cytotoxicity. Cancer Research 61 577-581.

Mitsiades CS, Mitsiades N, Poulaki V, Schlossman R, Akiyama M, Chauhan D, Hideshima T, Treon SP, Munshi NC, Richardson PG et al. 2002 Activation of NF-kappaB and upregulation of intracellular anti-apoptotic proteins via the IGF-I/Akt signaling in human multiple myeloma cells: therapeutic implications. Oncogene 21 5673-5683.

Moss ML, Jin SL, Milla ME, Bickett DM, Burkhart W, Carter HL, Chen WJ, Clay WC, Didsbury JR, Hassler D et al. 1997 Cloning of a disintegrin metalloproteinase that processes precursor tumournecrosis factor-alpha. [Erratum appears in Nature 1997386738.$]$ Nature 385 733-736.

Munster PN, Srethapakdi M, Moasser MM \& Rosen N 2001 Inhibition of heat shock protein 90 function by ansamycins causes the morphological and functional differentiation of breast cancer cells. Cancer Research 61 2945-2952.

Muschen M, Warskulat U \& Beckmann MW 2000 Defining CD95 as a tumor suppressor gene. Journal of Molecular Medicine 78 312-325.

Muzio M, Stockwell BR, Stennicke HR, Salvesen GS \& Dixit VM 1998 An induced proximity model for caspase- 8 activation. Journal of Biological Chemistry 273 2926-2930.

Myc A, Arscott PL, Bretz JD, Thompson NW \& Baker JR Jr 1999 Characterization of FAP-1 expression and function in thyroid follicular cells. Endocrinology 140 5431-5434.

Nambu Y, Hughes SJ, Rehemtulla A, Hamstra D, Orringer MB \& Beer DG 1998 Lack of cell surface Fas/APO-1 expression in pulmonary adenocarcinomas. Journal of Clinical Investigation 101 1102-1110.

Niehans GA, Brunner T, Frizelle SP, Liston JC, Salerno CT, Knapp DJ, Green DR \& Kratzke RA 1997 Human lung carcinomas express Fas ligand. Cancer Research 57 1007-1012.

O'Connell J, O'Sullivan GC, Collins JK \& Shanahan F 1996 The Fas counterattack: Fas-mediated T cell killing by colon cancer cells expressing Fas ligand. Journal of Experimental Medicine 184 1075-1082.

Ogasawara J, Watanabe-Fukunaga R, Adachi M, Matsuzawa A, Kasugai T, Kitamura Y, Itoh N, Suda T \& Nagata S 1993 Lethal effect of the anti-Fas antibody in mice. Nature $364806-809$.

Ohta K, Pang XP, Berg L \& Hershman JM 1996 Antitumor actions of cytokines on new human papillary thyroid carcinoma cell lines. Journal of Clinical Endocrinology and Metabolism 81 2607-2612.

Ozoren N \& El-Deiry WS 2003 Cell surface death receptor signaling in normal and cancer cells. Seminars in Cancer Biology 13 135-147.
Ozoren N, Kim K, Burns TF, Dicker DT, Moscioni AD \& El-Deiry WS 2000 The caspase 9 inhibitor Z-LEHD-FMK protects human liver cells while permitting death of cancer cells exposed to tumor necrosis factor-related apoptosis-inducing ligand. Cancer Research $\mathbf{6 0}$ 6259-6265.

Pang XP, Hershman JM, Chung M \& Pekary AE 1989

Characterization of tumor necrosis factor-alpha receptors in human and rat thyroid cells and regulation of the receptors by thyrotropin. Endocrinology 125 1783-1788.

Pang XP, Ross NS, Park M, Juillard GJ, Stanley TM \& Hershman JM 1992 Tumor necrosis factor-alpha activates nuclear factor kappa $\mathrm{B}$ and induces manganous superoxide dismutase and phosphodiesterase mRNA in human papillary thyroid carcinoma cells. Journal of Biological Chemistry 267 12826-12830.

Pang XP, Ross NS \& Hershman JM 1996 Alterations in TNF-alpha signal transduction in resistant human papillary thyroid carcinoma cells. Thyroid 6 313-317.

Pang XP, Hershman JM \& Karsan A 1997 TNF-alpha induction of A1 expression in human cancer cells. Oncology Research 9 623-627.

Poulaki V, Mitsiades CS, Kotoula V, Tseleni-Balafouta S, Ashkenazi A, Koutras DA \& Mitsiades N 2002 Regulation of Apo2L/tumor necrosis factor-related apoptosis-inducing ligand-induced apoptosis in thyroid carcinoma cells. American Journal of Pathology 161 643-654.

Present DH, Rutgeerts P, Targan S, Hanauer SB, Mayer L, van Hogezand RA, Podolsky DK, Sands BE, Brakman T, DeWoody KL et al. 1999 Infliximab for the treatment of fistulas in patients with Crohn's disease. New England Journal of Medicine $\mathbf{3 4 0}$ 1398-1405.

Rabinowich H, Reichert TE, Kashii Y, Gastman BR, Bell MC \& Whiteside TL 1998 Lymphocyte apoptosis induced by Fas ligandexpressing ovarian carcinoma cells. Implications for altered expression of $\mathrm{T}$ cell receptor in tumor-associated lymphocytes. Journal of Clinical Investigation 101 2579-2588.

Ringel MD, Hayre N, Saito J, Saunier B, Schuppert F, Burch H, Bernet V, Burman KD, Kohn LD \& Saji M 2001 Overexpression and overactivation of Akt in thyroid carcinoma. Cancer Research 61 6105-6111.

Saas P, Walker PR, Hahne M, Quiquerez AL, Schnuriger V, Perrin G, French L, Van Meir EG, de Tribolet N, Tschopp J \& Dietrich PY 1997 Fas ligand expression by astrocytoma in vivo: maintaining immune privilege in the brain? Journal of Clinical Investigation 99 $1173-1178$

Saito J, Kohn AD, Roth RA, Noguchi Y, Tatsumo I, Hirai A, Suzuki K, Kohn LD, Saji M \& Ringel MD 2001 Regulation of FRTL-5 thyroid cell growth by phosphatidylinositol (OH) 3 kinase-dependent Akt-mediated signaling. Thyroid 11 339-351.

Salcedo TW, Alderson RF, Basu S, Beatty S, Choi GH, Corcoran M, Halpern W, Gentz S, Gregorio T, Grzegorzewski KJ, Kanakaraj P. 2002 TRM-1, a fully human TRAIL-R1 agonistic monoclonal antibody, displays in vitro and in vivo anti-tumor activity. Proceedings of the American Association for Cancer Research 43856.

Salvesen GS \& Dixit VM 1999 Caspase activation: the inducedproximity model. PNAS 96 10964-10967.

Schulze-Osthoff K, Ferrari D, Los M, Wesselborg S \& Peter ME 1998 Apoptosis signaling by death receptors. European Journal of Biochemistry 254 439-459.

Shingu K, Sugenoya A, Itoh N \& Kato R 1994 Expression of basic fibroblast growth factor in thyroid disorders. World Journal of Surgery 18 500-505.

Shingu K, Fujimori M, Ito K, Hama Y, Kasuga Y, Kobayashi S, Itoh N \& Amano J 1998 Expression of fibroblast growth factor-2 and fibroblast growth factor receptor-1 in thyroid diseases: difference between neoplasms and hyperplastic lesions. Endocrine Journal $\mathbf{4 5}$ 35-43.

Simpson SQ \& Casey LC 1989 Role of tumor necrosis factor in sepsis and acute lung injury. Critical Care Clinics 5 27-47. 
Sprick MR, Weigand MA, Rieser E, Rauch CT, Juo P, Blenis J, Krammer PH \& Walczak H 2000 FADD/MORT1 and caspase-8 are recruited to TRAIL receptors 1 and 2 and are essential for apoptosis mediated by TRAIL receptor 2. Immunity 12 599-609.

Stassi G \& De Maria R 2002 Autoimmune thyroid disease: new models of cell death in autoimmunity. Nature Reviews. Immunology 2 195-204.

Stassi G, Di Liberto D, Todaro M, Zeuner A, Ricci-Vitiani L, Stoppacciaro A, Ruco L, Farina F, Zummo G \& De Maria R 2000 Control of target cell survival in thyroid autoimmunity by $\mathrm{T}$ helper cytokines via regulation of apoptotic proteins. Nature Immunology $\mathbf{1}$ 483-488.

Tanimoto C, Hirakawa S, Kawasaki H, Hayakawa N \& Ota Z 1995 Apoptosis in thyroid diseases: a histochemical study. Endocrine Journal 42 193-201.

Tartaglia LA, Pennica D \& Goeddel DV 1993 Ligand passing: the 75-kDa tumor necrosis factor (TNF) receptor recruits TNF for signaling by the $55-\mathrm{kDa}$ TNF receptor. Journal of Biological Chemistry 268 18542-18548.

Thome M, Schneider P, Hofmann K, Fickenscher H, Meinl E, Neipel F, Mattmann C, Burns K, Bodmer JL, Schroter M et al. 1997 Viral FLICE-inhibitory proteins (FLIPs) prevent apoptosis induced by death receptors. Nature 386 517-521.

Thompson CB 1995 Apoptosis in the pathogenesis and treatment of disease. Science 267 1456-1462.

Tracey KJ 1991 Tumor necrosis factor (cachectin) in the biology of septic shock syndrome. Circulatory Shock 35 123-128.

Tsatsoulis A 2002 The role of apoptosis in thyroid disease. Minerva Medica 93 169-180.

van der Laan BF, Freeman JL \& Asa SL 1995 Expression of growth factors and growth factor receptors in normal and tumorous human thyroid tissues. Thyroid 5 67-73.
Vella V, Sciacca L, Pandini G, Mineo R, Squatrito S, Vigneri R \& Belfiore A 2001 The IGF system in thyroid cancer: new concepts. Molecular Pathology 54 121-124.

Vinay DS \& Kwon BS 1998 Role of 4-1BB in immune responses. Seminars in Immunology 10 481-489.

Walczak H, Miller RE, Ariail K, Gliniak B, Griffith TS, Kubin M, Chin W, Jones J, Woodward A, Le T et al. 1999 Tumoricidal activity of tumor necrosis factor-related apoptosis-inducing ligand in vivo. Nature Medicine 5 157-163.

Wang CY, Zhong WB, Chang TC, Lai SM \& Tsai YF 2002 Tumor necrosis factor alpha induces three-dimensional cytomorphologic differentiation of human anaplastic thyroid carcinoma cells through activation of nuclear factor kappaB. Cancer 95 1827-1833.

Weetman AP \& McGregor AM 1994 Autoimmune thyroid disease: further developments in our understanding. Endocrine Reviews $\mathbf{1 5}$ 788-830.

Weinblatt ME, Kremer JM, Bankhurst AD, Bulpitt KJ, Fleischmann RM, Fox RI, Jackson CG, Lange M \& Burge DJ 1999 A trial of etanercept, a recombinant tumor necrosis factor receptor:Fc fusion protein, in patients with rheumatoid arthritis receiving methotrexate [Comment]. New England Journal of Medicine 340 253-259.

Westermark K, Lundqvist M, Wallin G, Dahlman T, Hacker GW, Heldin NE \& Grimelius L 1996 EGF-receptors in human normal and pathological thyroid tissue. Histopathology 28 221-227.

Zhivotovsky B \& Orrenius S 2003 Defects in the apoptotic machinery of cancer cells: role in drug resistance. Seminars in Cancer Biology 13 $125-134$.

Received 10 March 2003

Accepted 9 May 2003 